\title{
A COTS-Style Acquisition Strategy for Human Exploration Beyond LEO
}

\author{
Dr. Dale Arney ${ }^{1}$, Kevin Earle ${ }^{1}$, Jordan Klovstad ${ }^{1}$, and Christopher Jones ${ }^{1}$ \\ NASA Langley Research Center, Hampton, VA 23681
}

\begin{abstract}
The Evolvable Mars Campaign presents a long term strategy for NASA's Journey to Mars within a capability driven framework. By comparing each element to a set of criteria, this paper reviews the potential of acquiring those capabilities using a strategy similar to the Commercial Orbital Transportation Services program. The paper presents the criteria, assesses the elements against those criteria, and then discusses the suitability of each element to being developed using this acquisition strategy. Throughout the campaign, certain capabilities are well suited to being developed in this manner while others are not. This assessment is a snapshot in time, and should be revisited as the campaign and/or commercial capabilities change.
\end{abstract}

\section{Introduction}

The Evolvable Mars Campaign (EMC) is an ongoing series of architectural trade analyses that defines the capabilities and elements needed for a sustainable human presence on the surface of Mars. The point of departure used in EMC was presented at the AIAA SPACE 2015 conference, ${ }^{1,2,3,4,5,6,7,8}$ which included the strategy, campaign, architecture, and elements. Beyond the current developments of the Space Launch System (SLS) and Orion, EMC has not discussed the details on the acquisition strategy for any requisite elements.

Zuniga et al. (2015) ${ }^{9}$ proposed a lunar exploration campaign that economically extracts resources to produce propellant in support of a Mars exploration campaign. In the paper, the authors used a structured, criteria-based process to assess the suitability for multiple elements within the architecture to be developed using an alternative acquisition strategy. ${ }^{9}$ This strategy was used in the Commercial Orbital Transportation Services (COTS) program, and it has led to the affordable delivery of cargo, and soon crew, to the International Space Station (ISS). This paper uses that assessment as inspiration and a starting point to assess the suitability of a similar acquisition strategy for NASA's Journey to Mars.

\section{Background}

\section{A. Commercial Orbital Transportation Services (COTS)}

In 2005, the Commercial Orbital Transportation Services (COTS) program was started to develop an alternative commercial crew and cargo delivery capability to the International Space Station (ISS). At the time, the Space Shuttle was going to end without a means to access ISS until the crew launch vehicle, Ares I, was ready under the Constellation Program. The goal of the COTS

\footnotetext{
${ }^{1}$ Aerospace Engineer, Space Mission Analysis Branch, MS 462, AIAA Member
} 
program was to develop a commercial option to fill that void, which would also stimulate industry and lower the cost of access to ISS. ${ }^{10}$

An acquisition strategy was pursued to allow NASA to invest in the emerging commercial space sector to develop and operate these new capabilities. Funded Space Act Agreements (SAAs) and firm-fixed price service contracts were used instead of the traditional Federal Acquisition Regulation (FAR) cost plus acquisition approach. The key attributes of this COTS-like acquisition strategy, as detailed by Zuniga et al. (2015), ${ }^{9}$ are enumerated below. They represent the best practices of this acquisition approach to achieving the cost savings that were realized by the COTS program.

1. NASA and commercial partners share cost, development, and operational risk.

2. NASA makes long-term commitments to procure commercial services - this helps secure private investments to augment the NASA investment.

3. NASA encourages commercial partners to target other markets outside of NASA - NASA is an anchor tenant, but not the only customer.

4. NASA uses SAAs to enter into partnerships with the commercial providers - this increases flexibility in design solutions relative to the FAR-based approach.

5. NASA pays on the performance of specific milestones - this provides off-ramps and reduces programmatic risk.

6. Commercial partners retain intellectual property rights, and the partners own and operate their developed systems.

Initially, the COTS program used funded SAAs to develop the commercial capability to deliver pressurized and unpressurized cargo using commercial providers. For a total NASA investment of $\$ 800 \mathrm{M}^{10}$ along with providing technical assistance to companies and private funds raised by the commercial partners themselves, the program developed two medium lift launch vehicles and two automated cargo spacecraft. Under the COTS program, SpaceX had developed the Falcon 9 launch vehicle and cargo Dragon capsule, and Orbital Sciences had developed the Antares launch vehicle and Cygnus spacecraft. ${ }^{10}$ For comparison, the Ares I-X test launch, which was a flight test of a similar class launch vehicle, reportedly cost $\$ 445 \mathrm{M}^{11}$

The Commercial Resupply Services (CRS) contract awarded SpaceX and Orbital Sciences twenty total resupply missions at a cost of \$3.5B. October 2012 saw the first CRS resupply flight to ISS with the SpaceX Dragon delivering cargo to ISS and returning to Earth. At the time of this writing, SpaceX has delivered a total of eight resupply flights, ${ }^{12}$ and Orbital has delivered five, ${ }^{13}$ with each system experiencing a failure and a subsequent return to operation. In January 2016, the second round of CRS added Sierra Nevada's Dream Chaser vehicle and the total contract across all three providers is worth a potential \$14B to provide cargo delivery and return to ISS through $2024 .^{14}$

The Commercial Crew program had a similar two-phase program structure, with the first phase providing funded SAAs to develop the required systems and the second procuring the commercial services. Development of the crew systems started in 2010 with the Commercial Crew Development (CCDev) program. Multiple companies participated in this phase of 
development, including SpaceX, Boeing, and Sierra Nevada. The program continued through multiple phases and down-selects until the Commercial Crew Transportation Capability (CCtCap) service contracts were awarded in September 2014 to SpaceX and Boeing. These contract totaled $\$ 6.8 \mathrm{~B}$ ( $\$ 2.6 \mathrm{~B}$ to SpaceX, $\$ 4.2 \mathrm{~B}$ to Boeing) for services beginning no later than $2017 .{ }^{10}$

\section{B. Evolvable Mars Campaign}

The Evolvable Mars Campaign (EMC) is an ongoing activity within NASA to define the capabilities and elements needed for NASA's Journey to Mars. The EMC uses a phased approach, beginning with Earth Reliant missions to expand knowledge and operations in space. Proving Ground missions follow in cislunar space, which focus on validating key transportation and habitation elements as well as demonstrating operational capabilities in a deep space environment. Finally, Earth Independent missions at Mars focus on exploring the Mars system, including the surface, orbit, and Mars moons. ${ }^{1}$ Figure 1 provides a graphical representation of this phased approach.

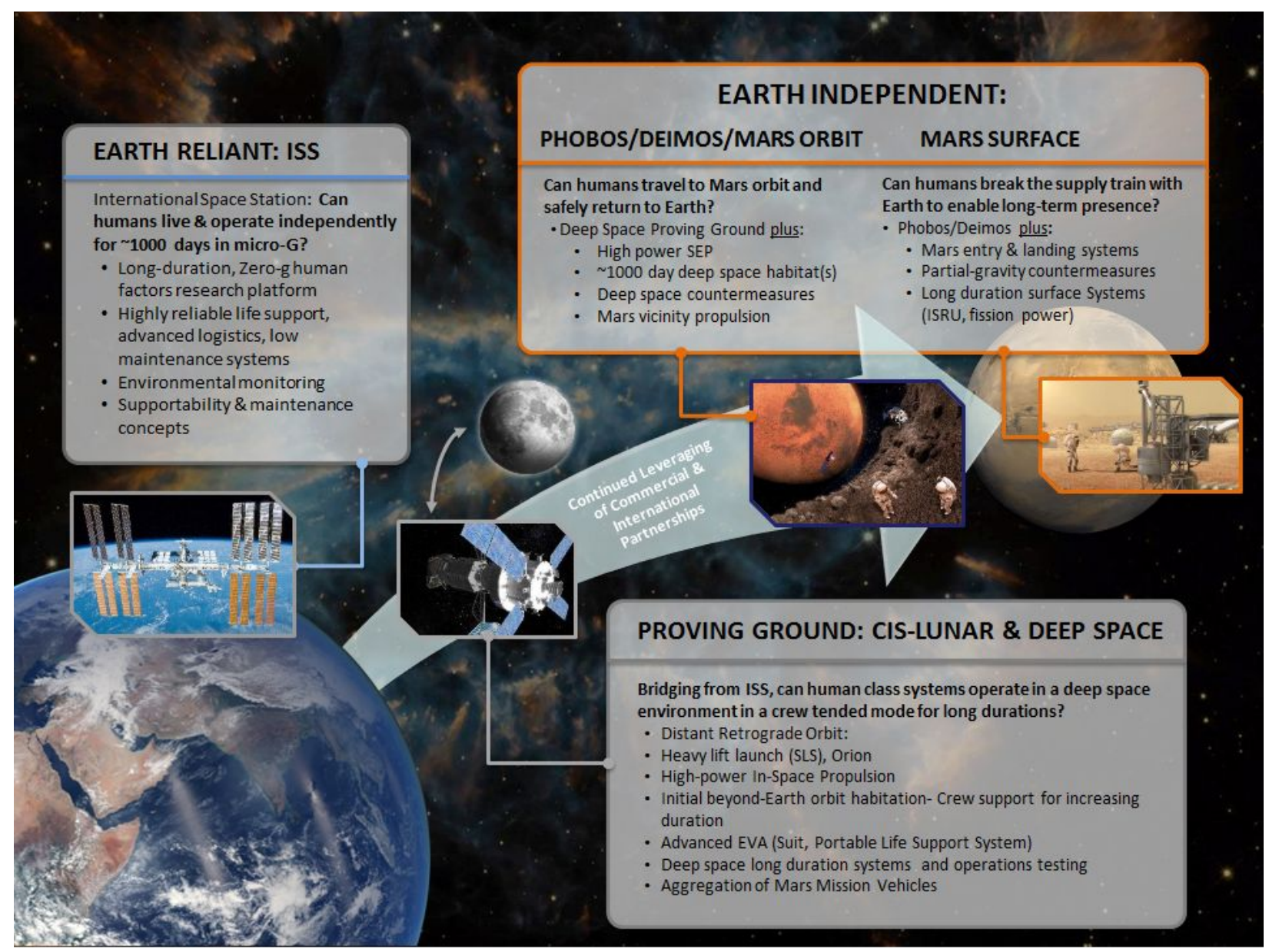

Figure 1: Evolvable Mars Campaign (EMC) Mission Phases (source: NASA)

The ground rules for the EMC state that, in sending humans to the Mars system in the 2030s, the architecture must use the Space Launch System (SLS), Orion crew vehicle, and Solar Electric Propulsion (SEP) derived from the Asteroid Redirect Vehicle (ARV). ${ }^{1}$ The EMC point of departure considers two in-space transportation options: the Split SEP-Chemical approach and the Hybrid 
approach. The Split SEP-Chemical approach uses low-thrust SEP to pre-deploy cargo to the Mars system followed by high-thrust Liquid Oxygen/Liquid Methane $\left(\mathrm{LOX} / \mathrm{CH}_{4}\right)$ propulsive stages to transport the crew and in-space habitation. In this approach, the cargo flights (i.e. landers) aerocapture into Mars orbit while the crew systems are propulsively captured into Mars orbit. ${ }^{3}$ The Hybrid approach uses a single system that contains both the SEP system and a chemical propulsion system to deliver both crew and cargo. These Hybrid Propulsion Systems deliver payload to Mars orbit without aerocapture and then return to cislunar space in order to be reused on subsequent missions. ${ }^{2}$ Both concepts use similar capabilities for Entry, Descent, and Landing (EDL) and ascent, ${ }^{6}$ habitation, ${ }^{4}$ and surface operations. ${ }^{5}$

\section{Functional Decomposition of EMC}

To assess how a COTS-style acquisition could be applied to the EMC, the capabilities and elements needed for the EMC must first be identified. The capabilities needed for the three EMC phases are enumerated in Tables 1-3 along with descriptions of each item. These capabilities must be achieved to perform the EMC, regardless of the acquisition strategy (COTS or a more traditional approach).

Table 1: Overview of Elements and Capabilities in the EMC - Cislunar Missions

\begin{tabular}{ll}
\hline \multicolumn{1}{c}{ Element } & \multicolumn{1}{c}{ Functional Description } \\
\hline SLS Cargo Delivery & $\begin{array}{l}\text { Large cargo delivery to cislunar space (volume is } \\
\text { primary driver) }\end{array}$ \\
\hline SLS Crew Delivery & Crew delivery to cislunar space \\
\hline Logistics Delivery & $\begin{array}{l}\text { Deliver logistics (e.g. consumables, spares) to cislunar } \\
\text { space }\end{array}$ \\
\hline Asteroid Redirect Vehicle (ARV) & $\begin{array}{l}\text { Return boulder from Near Earth Asteroid (NEA) with } \\
\text { 40-kW class SEP, asteroid capture mechanism }\end{array}$ \\
\hline Resource Prospecting on the Moon & $\begin{array}{l}\text { Rover and ISRU technologies to prospect lunar } \\
\text { resources }\end{array}$ \\
\hline Cislunar Habitat & $\begin{array}{l}\text { Support longer duration cislunar missions (up to 60 } \\
\text { days) and provide EVA capability }\end{array}$ \\
\hline
\end{tabular}


Table 2: Overview of Elements and Capabilities in the EMC - Mars Vicinity Missions

\begin{tabular}{ll}
\hline \multicolumn{1}{c}{ Element } & \multicolumn{1}{c}{ Functional Description } \\
\hline Long Duration Habitat & $\begin{array}{l}\text { Transit, Phobos, and surface habitats, support crew of } \\
\text { 4 for up to } 1100 \text { days in deep space or on the surface }\end{array}$ \\
\hline LOX $/ \mathrm{CH}_{4}$ Propulsion Stage & $\begin{array}{l}\text { Disposable } \mathrm{LOX} / \mathrm{CH}_{4} \text { stage to deliver crew to Mars } \\
\text { system, uses common Mars descent/ascent engine }\end{array}$ \\
\hline Solar Electric Propulsion Stage & $\begin{array}{l}\text { Disposable } 150-\mathrm{kW} \text { class SEP stage to deliver cargo to } \\
\text { Mars system }\end{array}$ \\
\hline Hybrid Propulsion System & $\begin{array}{l}\text { Reusable } 300-\mathrm{kW} \text { class SEP and storable propellant } \\
\text { system to deliver crew and cargo to Mars surface then } \\
\text { return to cislunar, capable of refueling }\end{array}$ \\
\hline Cislunar Propellant Delivery & $\begin{array}{l}\text { Deliver propellant (e.g. xenon, storable propellants, } \\
\text { pressurant gas) to cislunar space to be used by Hybrid }\end{array}$ \\
\hline Taxi or Excursion Vehicle & $\begin{array}{l}\text { Support crew for short duration to provide mobility } \\
\text { within the Mars vicinity and on the surface of Phobos }\end{array}$ \\
\hline
\end{tabular}

\section{Earth-to-Orbit and In-Space Transportation}

In the EMC, the SLS and Orion provide the function of delivering crew and cargo to cislunar space. For the analysis in this paper, the payload types that SLS delivers to cislunar space are considered separately to assess the ability for COTS-style services to augment the NASA capability. Refuelling flights (in the Hybrid option) and logistics delivery to cislunar space are performed by the SLS under the EMC, but have the potential to be delivered commercially.

The Asteroid Redirect Vehicle (ARV) is advancing the state of SEP thrusters, arrays, and operations by retrieving a boulder from a Near Earth Asteroid (NEA) and returning to cislunar space. The Hybrid in-space transportation option leverages this capability by using high-power SEP (300-kW class) and state-of-the-art storable propulsion systems. It is capable of delivering the Mars elements to Martian orbit, returning to cislunar space, and being refueled and reused for two additional missions. The Split SEP-Chemical option also leverages the ARV SEP with a 150-kW class SEP to deliver cargo. Advanced $\mathrm{LOX} / \mathrm{CH}_{4}$ propulsion delivers the crew to Mars and returns them to Earth. This engine is potentially the same engine as the Mars surface access engine used for descent and ascent., ${ }^{2,3}$ 
Table 3: Overview of Elements and Capabilities in the EMC - Mars Surface Missions

\begin{tabular}{ll}
\hline \multicolumn{1}{c}{ Element } & \multicolumn{1}{c}{ Functional Description } \\
\hline Mars Descent Vehicle & $\begin{array}{l}\text { Deliver 18-20 t of payload to the Mars surface from } \\
\text { Martian orbit }\end{array}$ \\
\hline Mars Ascent Vehicle & $\begin{array}{l}\text { Deliver 4 crew to Martian orbit after surface mission, } \\
\text { support crew for up to } 5 \text { days during transit, refuel } \\
\text { with ISRU-produced propellant }\end{array}$ \\
\hline $\begin{array}{l}\text { In-Situ Resource Utilization (ISRU) } \\
\text { Plant }\end{array}$ & Produce $\sim 2$ kg/hr of oxygen for the ascent vehicle \\
\hline Surface Power System & $\begin{array}{l}\text { Generate 10s of kW of power for the surface systems, } \\
\text { including ISRU plant and ascent vehicle fluid } \\
\text { management }\end{array}$ \\
\hline $\begin{array}{l}\text { Communications Infrastructure } \\
\text { surface and orbit) }\end{array}$ & $\begin{array}{l}\text { Provide high speed communications and navigation } \\
\text { capability in the Mars system and on the surface }\end{array}$ \\
\hline Surface Pressurized Rover & $\begin{array}{l}\text { Provide transportation of crew, similar to the taxi/ } \\
\text { excursion vehicle for Phobos, and provide EVA }\end{array}$ \\
\hline Surface Robotic Rover & $\begin{array}{l}\text { Add to human capability with autonomous scouting, } \\
\text { deployment of surface systems, and other functions }\end{array}$ \\
\hline
\end{tabular}

\section{Habitation}

Advances in crew habitation in deep space begin with the initial cislunar habitat, which is a testbed for advanced systems and an augmentation module for the Orion to enable longer duration missions in cislunar space. These longer missions can last up to 60 days and include Extravehicular Activity (EVA) capability. This initial capability is leveraged to create long duration habitats (transit, Phobos, and surface habitats are all similar long duration habitats supporting crew up to 1100 days) and short duration habitats used in the Mars vicinity (ascent vehicle, rovers, and taxi vehicles). ${ }^{1,4,5}$

\section{Surface Access and Destination Systems}

The key capability for the Mars surface missions is surface access. The Mars lander requires advancements in Entry, Descent, and Landing (EDL) of large payloads (18-20 t for EMC), including supersonic retropropulsion and precision landing. An ascent vehicle must also deliver the crew to Mars orbit, where the transit habitat is waiting. The ascent vehicle must survive in a dormant state for long durations on the surface, be refueled, and support the crew for multiple days. ${ }^{6}$

Along with the transportation and habitation systems, destination systems provide critical functionality for Mars vicinity and surface missions. In-Situ Resource Utilization (ISRU) provides the propellant to fuel the ascent stage, while surface nuclear power provides power to the ISRU 
system, propellant management system on the ascent vehicle, and other Mars surface systems. The Phobos Exploration Vehicle (PEV) enables mobile exploration of Phobos, while the pressurized rover enables mobile exploration of the Martian surface. Finally, robotic systems like rovers and communications infrastructure provide critical functions for a Mars mission. ${ }^{5}$

\section{Potential for COTS-Style Acquisition in EMC}

\section{A. Criteria}

Several criteria are needed to assess the potential for an EMC element to be developed in a COTS-style manner. The set of criteria used to compare these elements, as inspired by those used in Zuniga et al. (2015), ${ }^{9}$ are presented in Table 4. This table provides brief descriptions of the criteria and the definition of the levels against which each element is rated. While this set of criteria is not complete, they provide insight into the potential for a given element to be pursued as a COTS-style acquisition. The data presented in this paper is a snapshot in time for both the EMC and the commercial partners' capabilities, so these ratings can and will change in the future. For that reason, the three mission types of the EMC (cislunar, Mars vicinity, and Mars surface) are considered separately, so the assessment of the near-term missions in cislunar has more fidelity than the assessments of the latter missions.

The "Maturity of the Capability" criterion assesses how well the function is understood and how easily an industry partner could perform that function. A Low score in this criterion indicates that this capability does not exist elsewhere in the industry. A Med score indicates that some advancement in the capability will be needed before industry can perform the needed function. A High score indicates that the capability already exists in the industry, and applying that capability to the EMC would require little advancement in the capability.

The "Availability of Viable Companies" criterion assesses how many companies are actively pursuing this function. Some instances require assumptions on how well a given company's current activities can translate to the desired function. A Low score in this criterion indicates that no existing companies could perform this function. A Med score in this criterion indicates that one or two companies have the ability to perform this function, and a High score indicates that many existing companies could perform this function. 
Table 4: Description of COTS Acquisition Criteria for EMC Assessment

\begin{tabular}{|c|c|c|c|c|}
\hline Name & Description & Low & Med & High \\
\hline $\begin{array}{l}\text { Maturity of the } \\
\text { Capability }\end{array}$ & $\begin{array}{l}\text { Readiness of industry to } \\
\text { perform successfully in an } \\
\text { operational space } \\
\text { environment }\end{array}$ & $\begin{array}{l}\text { No similar } \\
\text { capability } \\
\text { exists }\end{array}$ & $\begin{array}{c}\text { Some basic } \\
\text { advancement } \\
\text { needed }\end{array}$ & $\begin{array}{l}\text { Capability } \\
\text { currently } \\
\text { exists }\end{array}$ \\
\hline $\begin{array}{l}\text { Availability of } \\
\text { Viable } \\
\text { Companies }\end{array}$ & $\begin{array}{l}\text { Number of viable } \\
\text { companies with the } \\
\text { ability to perform the } \\
\text { proposed function }\end{array}$ & 0 & $1-2$ & $3+$ \\
\hline $\begin{array}{l}\text { Significant } \\
\text { Market } \\
\text { Outside of } \\
\text { NASA }\end{array}$ & $\begin{array}{l}\text { Measure of potential for } \\
\text { emergence of markets } \\
\text { beyond NASA's needs }\end{array}$ & NASA only & $\begin{array}{l}\text { NASA as } \\
\text { primary } \\
\text { customer/ } \\
\text { tenant }\end{array}$ & $\begin{array}{l}\text { NASA is one of } \\
\text { many } \\
\text { customers }\end{array}$ \\
\hline $\begin{array}{l}\text { Likelihood of } \\
\text { Low Risk to } \\
\text { the } \\
\text { Architecture }\end{array}$ & $\begin{array}{l}\text { Inverse of the potential } \\
\text { risk that this element } \\
\text { contributes to the } \\
\text { architecture }\end{array}$ & $\begin{array}{l}\text { High Risk, in } \\
\text { the critical } \\
\text { path, single } \\
\text { point failures }\end{array}$ & Moderate Risk & $\begin{array}{l}\text { Low Risk, out } \\
\text { of the critical } \\
\text { path, } \\
\text { redundancy } \\
\text { elsewhere in } \\
\text { the arch. }\end{array}$ \\
\hline $\begin{array}{l}\text { Reduction in } \\
\text { NASA } \\
\text { Investment }\end{array}$ & $\begin{array}{l}\text { Potential for reduction in } \\
\text { NASA's investment to } \\
\text { achieve the capability } \\
\text { required in the } \\
\text { architecture }\end{array}$ & $\begin{array}{l}\text { Low potential } \\
\text { reduction } \\
(\leq \$ 1 \mathrm{M})\end{array}$ & $\begin{array}{l}\text { Moderate } \\
\text { potential } \\
\text { reduction } \\
(\$ 10 \mathrm{~s}-\$ 100 \mathrm{~s} \\
\mathrm{M})\end{array}$ & $\begin{array}{l}\text { High potential } \\
\text { reduction } \\
\quad(\geq \$ 1 B)\end{array}$ \\
\hline
\end{tabular}

The "Significant Market Outside of NASA" criterion assesses how the operational cost can be split with multiple customers. A Low score in this criterion indicates that NASA would be the only customer, and costs would not be split among multiple missions. A Med score indicates that NASA would be the primary customer with other customers accounting for a small portion of the total market. A High score indicates that NASA would be one of many customers, and fixed costs would be amortized over many uses, thereby reducing the cost per use.

The "Likelihood of Low Risk to the Architecture" criterion assesses how much risk that particular element contributes to the total architecture and campaign. A Low score in this criterion indicates that the element is a high risk element that is in the critical path and/or has single point failures. A High score in this criterion indicates that the element is a low risk element that is out of the critical path and has functional redundancies in the architecture. A Med score indicates a moderate level of risk somewhere between the Low and High scores. 
Finally, the "Reduction in NASA Investment" criterion assesses the potential for cost savings by using a COTS-style acquisition strategy as defined earlier in this paper. A Low score indicates that a small reduction in cost (less than $\$ 1 \mathrm{M}$ ) is achievable. This is either due to the capability being a small magnitude investment in the first place or the amount of investment needed to develop that capability would be large regardless of the acquisition strategy (e.g. basic research). A Mid score indicates a cost reduction of 10 s or 100 s of millions of dollars. Finally, a High score in this criterion indicates that a significant savings is achievable, over $\$ 1 \mathrm{~B}$.

\section{B. Mapping to the EMC and Discussion}

The assessment of the potential for EMC elements to be acquired using a COTS-style strategy is presented in the following sections. The assessment is divided into cislunar missions, Mars vicinity missions, and Mars surface missions. This assessment indicates which elements are worthy of further study into acquiring them with a COTS-style acquisition strategy, and should not be considered definitive. Many other metrics must be considered before making an acquisition decision, and the snapshot in time of the EMC and the criteria assessment will change in the future.

\section{Cislunar Missions}

The assessment of the EMC elements that support the cislunar missions is presented in Table 5. The ARV proves to be the most challenging to pursue a COTS-style acquisition strategy. The potential for a market exists in the asteroid mining community, and the ARV itself is out of the critical path of the human exploration missions in cislunar. However, the development of a SEP system in this class and the lack of companies doing so outside of NASA's planned mission indicates that this element would have a low likelihood of reducing NASA's investment on this capability.

Delivery of crew and large cargo (volume and mass) could be considered for COTS-style acquisition, as the launch market is well developed and there are many suppliers in the medium-class launch vehicle market. Launch cost is a driving cost for any architecture, and having multiple providers would also reduce risk of launch delays, similar to the way SpaceX and Orbital were able to continue supplying the ISS during their launch failures. However, heavy lift capability, especially with large diameter payloads, does not exist in the market yet. SpaceX plans to launch their heavy lift launch vehicle, the Falcon Heavy within a year, and the company will be announcing a larger Mars Colonial Transporter in 2016. ${ }^{19}$ United Launch Alliance has plans to evolve the Vulcan launch vehicle to accommodate large payloads as well. ${ }^{20}$ These two capabilities need more analysis to determine their suitability to being acquired in this alternative manner.

Finally, several capabilities in the cislunar mission element look promising. Cislunar habitation leverages technologies for human spaceflight from the past several decades, many commercial providers are working this area, and there is a potential market for this capability outside of NASA (e.g. hotels, commercial stations, science). This possibility is being pursued through the NextSTEP Broad Area Announcement (BAA). ${ }^{15}$ Logistics delivery to cislunar space is very similar to the current CRS contract. The performance is more demanding, and the market is not as well defined as it is for near-Earth space, but the ability to deliver the logistics as a service is 
analogous. Finally, lunar prospecting is being pursued in the commercial sector, primarily thanks to the Google Lunar XPRIZE. ${ }^{16}$ There is a potential for a market for ISRU and mining products, prospecting is sufficiently out of the critical path of the EMC, and the cost would be moderate for these robotic explorers.

Table 5: Assessment of EMC Elements in the Cislunar Missions

\begin{tabular}{l|c|c|c|c|c|}
\hline \multicolumn{1}{c}{} & \multicolumn{1}{c}{$\begin{array}{c}\text { Maturity of } \\
\text { Availability of } \\
\text { Viable } \\
\text { the Capability } \\
\text { Companies }\end{array}$} & $\begin{array}{c}\text { Significant } \\
\text { Market } \\
\text { Outside of } \\
\text { NASA }\end{array}$ & $\begin{array}{c}\text { Likelihood of } \\
\text { Low Risk to } \\
\text { the } \\
\text { Architecture }\end{array}$ & $\begin{array}{c}\text { Reduction in } \\
\text { NASA } \\
\text { Investment }\end{array}$ \\
\hline $\begin{array}{l}\text { SLS Cargo } \\
\text { Delivery }\end{array}$ & High & Med & Med & Med & High \\
\hline $\begin{array}{l}\text { SLS Crew } \\
\text { Delivery }\end{array}$ & High & Med & Med & Low & High \\
\hline $\begin{array}{l}\text { Logistics } \\
\text { Delivery }\end{array}$ & High & High & Med & High & High \\
\hline $\begin{array}{l}\text { Asteroid } \\
\text { Redirect } \\
\text { Vehicle (ARV) }\end{array}$ & Low & Low & Med & Med & Low \\
\hline $\begin{array}{l}\text { Resource } \\
\text { Prospecting } \\
\text { on the Moon }\end{array}$ & Med & High & Med & High & Med \\
\hline $\begin{array}{l}\text { Cislunar } \\
\text { habitat }\end{array}$ & High & Med & Med & Med & Med \\
\hline
\end{tabular}

\section{Mars Vicinity Missions}

The Mars vicinity missions leverage the knowledge gained during the cislunar missions. Therefore, the acquisition method of the cislunar missions as well as advancements in commercial capabilities during that time introduce significant uncertainty in the later mission phases. Conclusions drawn in this section, as well as the Mars surface missions section, are subject to change as the campaign and commercial capabilities evolve. The assessment for the Mars vicinity missions is presented in Table 6. 
Table 6: Assessment of EMC Elements in the Mars Vicinity Missions

\begin{tabular}{|c|c|c|c|c|c|}
\hline Element & $\begin{array}{l}\text { Maturity of } \\
\text { the Capability }\end{array}$ & $\begin{array}{c}\text { Availability of } \\
\text { Viable } \\
\text { Companies }\end{array}$ & $\begin{array}{l}\text { Significant } \\
\text { Market } \\
\text { Outside of } \\
\text { NASA }\end{array}$ & $\begin{array}{l}\text { Likelihood of } \\
\text { Low Risk to } \\
\text { the } \\
\text { Architecture }\end{array}$ & $\begin{array}{c}\text { Reduction in } \\
\text { NASA } \\
\text { Investment }\end{array}$ \\
\hline $\begin{array}{l}\text { Long } \\
\text { Duration } \\
\text { Habitat }\end{array}$ & High & Med & Med & Low & High \\
\hline $\begin{array}{l}{\mathrm{LOX} / \mathrm{CH}_{4}} \\
\text { Propulsion } \\
\text { Stage }\end{array}$ & Med & High & High & Low & Med \\
\hline $\begin{array}{l}\text { Solar Electric } \\
\text { Propulsion } \\
\text { Stage }\end{array}$ & Low & Low & Low & Med & Low \\
\hline $\begin{array}{l}\text { Hybrid } \\
\text { Propulsion } \\
\text { System }\end{array}$ & Low & Low & Low & Low & Low \\
\hline $\begin{array}{l}\text { Cislunar } \\
\text { Propellant } \\
\text { Delivery }\end{array}$ & Med & High & Med & High & High \\
\hline $\begin{array}{l}\text { Taxi or } \\
\text { Excursion } \\
\text { Vehicle }\end{array}$ & Med & Low & Low & Med & Med \\
\hline
\end{tabular}

The SEP Stage and the Hybrid Propulsion System, like the ARV before, suffer from the lack of heritage of high-power SEP. There is also little demand outside NASA for high power SEP, although lower power SEP and orbital solar power may benefit from these advancements. The cost savings of these two vehicles would be low because the element(s) will require significant technology and capability advancements, decreasing the likelihood that a COTS-style acquisition would be attractive. Note, however, that if the ARV were procured using a COTS-style mechanism, the assessment of these follow-on vehicles would change.

The taxi or excursion vehicle warrants further study. While no new technologies are required over those already in development, there are no companies developing these types of elements, and NASA would be the only customer. The element is not in the critical path, but it provides value to the mission, so losing it would impact the mission quality.

Finally, the long duration habitat, $\mathrm{LOX} / \mathrm{CH}_{4}$ stage, and propellant delivery are promising candidates to be acquired using a COTS-style strategy. Just like the cislunar habitat above, the 
long duration habitat will be well understood by the time an acquisition decision is required, has companies working on these types of elements, and has a potential market outside NASA. The long duration habitat will be more complex and expensive for these missions, but if the cislunar habitat is developed using a COTS-style strategy, there is a high likelihood that a COTS-style strategy would be pursued for the long duration habitat as well. $\mathrm{A} \mathrm{LOX} / \mathrm{CH}_{4}$ engine is in work by commercial companies, including SpaceX and Blue Origin, ${ }^{17,18}$ as this technology is applicable to other areas, such as the launch industry. The propulsive elements add significant risk in the architecture, and the $\mathrm{LOX} / \mathrm{CH}_{4}$ transports the crew. Finally, cislunar propellant delivery is similar to cislunar logistics delivery, with propellant transfer technology being the only significant difference between the two.

\section{Mars Surface Missions}

At the end of the EMC, the Mars surface missions leverage the capabilities developed in the previous two phases, cislunar and Mars vicinity. Table 7 presents the assessment of the EMC elements used in this mission phase.

Table 7: Assessment of EMC Elements in the Mars Surface Missions

\begin{tabular}{|c|c|c|c|c|c|}
\hline Element & $\begin{array}{l}\text { Maturity of } \\
\text { the Capability }\end{array}$ & $\begin{array}{c}\text { Availability of } \\
\text { Viable } \\
\text { Companies }\end{array}$ & $\begin{array}{l}\text { Significant } \\
\text { Market } \\
\text { Outside of } \\
\text { NASA }\end{array}$ & $\begin{array}{l}\text { Likelihood of } \\
\text { Low Risk to } \\
\text { the } \\
\text { Architecture }\end{array}$ & $\begin{array}{c}\text { Reduction in } \\
\text { NASA } \\
\text { Investment }\end{array}$ \\
\hline $\begin{array}{l}\text { Mars Descent } \\
\text { Vehicle }\end{array}$ & Low & Med & Low & Low & Low \\
\hline $\begin{array}{l}\text { Mars Ascent } \\
\text { Vehicle }\end{array}$ & Med & Low & Low & Low & Low \\
\hline ISRU Plant & Med & Med & Low & Low & Med \\
\hline $\begin{array}{l}\text { Surface } \\
\text { Power } \\
\text { System }\end{array}$ & Low & Low & Low & Low & Low \\
\hline $\begin{array}{l}\text { Comm. } \\
\text { Infrastructur } \\
\text { e }\end{array}$ & High & High & Med & High & Med \\
\hline $\begin{array}{l}\text { Surface } \\
\text { Pressurized } \\
\text { Rover }\end{array}$ & Med & Low & Low & Med & Med \\
\hline $\begin{array}{l}\text { Surface } \\
\text { Robotic } \\
\text { Rover }\end{array}$ & High & High & Med & High & Med \\
\hline
\end{tabular}


Many of these elements will be difficult to develop with a COTS-style strategy without significant changes in the technology and commercial sector beforehand. The Mars descent and ascent vehicles provide a significant technological challenge, are expected to be expensive, and are critical path elements to the architecture. Parts of these elements, such as the $\mathrm{LOX} / \mathrm{CH}_{4}$ engines, can be worked before the Mars surface missions, and the planned Red Dragon from SpaceX Mars landing may serve as a forerunner to future descent systems, ${ }^{19}$ but different subsystems and the scale of the EMC landers create significant differences from the Red Dragon. Surface nuclear power is another capability that requires technology development, has little industrial base or market outside of NASA, and will contribute a high risk and cost to the architecture.

Other surface systems, such as the ISRU plant and surface pressurized rover, would need further evaluation to determine if they are suitable for a COTS-style acquisition strategy. ISRU has been researched at a small scale and ISRU is being pursued outside of NASA, but it is difficult to imagine a Mars ISRU market outside of NASA in the near term, and it provides the critical function of producing the ascent propellant. Also, the surface pressurized rover is similar to the taxi, exploration vehicle, and cislunar habitat in function, but has different environment and operating conditions. If lunar and asteroid ISRU commercial industries are viable at the time, and if the ability to produce a surface pressurized rover is mature, these could be attractive options for COTS-style acquisition.

Finally, at this time, the support systems appear to be the best suited to use a COTS-style acquisition strategy. The communications infrastructure and robotic rovers are well outside of the critical path and/or will have plenty of redundant systems to account for potential element failures. These functions are well known, either from previous planetary work or Earth-based applications, and these two markets will likely grow in the future. Communications and autonomous navigation are being pursued on Earth to support a growing community of connected devices and autonomous transportation. Both of these functions would be better suited to a COTS-style acquisition strategy if similar functions in previous missions were also procured in this manner as well.

\section{Conclusions}

The Evolvable Mars Campaign (EMC) presents a long term strategy for NASA's Journey to Mars within a capability driven framework. A snapshot in time of the elements in the campaign and the ability of commercial partners to provide those elements is used in the paper. By comparing each element to a set of criteria, this paper reviewed the potential of developing those capabilities using an acquisition strategy similar to the Commercial Orbital Transportation Services (COTS) program. In the current EMC, launch services (especially for propellant and logistics), habitation, resource prospecting and robotics, and communications and navigation infrastructure are promising candidates for this alternative acquisition strategy. More complex systems that require a significant amount of technology and capability development, such as Mars surface access, nuclear power, and advanced in-space propulsion, may need a more 
traditional acquisition approach to account for uncertainty in the development phase. Finally, there are several capabilities that will need further study to determine if they are suitable for a COTS-style acquisition strategy, and this assessment will change over time as campaign and commercial capabilities change. The suitability is also a function of the acquisition approach used for similar elements in previous phases. This type of criteria-based assessment is valuable in determining the most cost-effective way to implement a strategy that advances human expansion through the Solar System.

\section{Acknowledgments}

The authors would like to acknowledge the inspiration and support from the authors of the Lunar COTS study heavily referenced in this paper: Allison Zuniga, Daniel Rasky, Edgar Zapata, Robert Pittman, and Roger Lepsch. The authors would also like to acknowledge the support and contributions of the members of the Space Mission Analysis Branch.

\section{References}

1. Craig, Douglas et al. "Pioneering Space Through an Evolvable Mars Campaign." AIAA Paper No. 2015-4409, 2015.

2. Merrill, Raymond et al. "An Integrated Hybrid Transportation Architecture for Human Mars Expeditions." AIAA Paper No. 2015-4442, 2015.

3. Percy, Thomas et al. "In-Space Transportation for NASA's Evolvable Mars Campaign." AIAA Paper No. 2015-4519, 2015.

4. Simon, Matthew et al. "Evolvable Mars Campaign Long Duration Habitation Strategies: Architectural Approaches to Enable Human Exploration Missions." AIAA Paper No. 2015-4514, 2015.

5. Toups, Larry and Hoffman, Stephen. "Pioneering Objectives and Activities on the Surface of Mars." AIAA Paper No. 2015-4410, 2015.

6. Polsgrove, Tara et al. "Mars Ascent Vehicle Design for Human Exploration." AIAA Paper No. 2015-4416, 2015.

7. Griffin, Brand et al. "Small Habitat Commonality Reduces Cost for Human Mars Missions." AIAA Paper No. 2015-4455, 2015.

8. Jeffries, Sharon et al. "Viability of a Reusable In-Space Transportation System." AIAA Paper No. 2015-4580, 2015.

9. Zuniga, Allison et al. "Lunar COTS: An Economic and Sustainable Approach to Reaching Mars." AIAA Paper No. 2015-4408, 2015.

10. NASA Johnson Space Center. Commercial Orbital Transportation Services: A New Era in Spaceflight. NASA SP-2014-617, 2014.

11. Harwood, William. "Ares I-X Rocket Hauled to Launch Pad for Critical Test Flight," CNET, October 2009. Accessed 7/25/2016.

12. “CRS-9 Dragon Resupply Mission,” SpaceX Press Kit. July 2016.

13. “Orbital ATK's Cygnus Spacecraft Successfully Launched on Fifth Cargo Delivery Mission to International Space Station," Orbital ATK Press Release. March 2016. 
14. "NASA Awards International Space Station Cargo Transport Contracts," NASA Press Release 16-007. January 2016.

15. "NASA Seeks Proposals for Deep Space Habitation Prototypes," NASA Press Release 16-045. April 2016.

16. Google Lunar XPRIZE Website. URL: http://lunar.xprize.org/. Accessed 7/25/2016.

17. Shotwell, Gwynne. Statement of Gwynne Shotwell President \& Chief Operating Officer Space Exploration Technologies Corp. (Spacex), Before the Committee on Armed Services, Subcommittee on Strategic Forces, U.S. House Of Representatives. March 17, 2015.

18. “BE-4 Rocket Engine.” Blue Origin Fact Sheet. Accessed 7/25/2016.

19. Davenport, Christian, "Elon Musk provides new details on his 'mind blowing' mission to Mars," Washington Post, June 2016.

20. DeRoy, Rich and Reed, John. "Vulcan, ACES and Beyond: Providing Launch Services for Tomorrow's Spacecraft." AAS Paper 16-052, 2016. 